\title{
Carrier-based pulse width modulation technique for a three-to-five phase matrix converter for supplying five-phase two-motor drives
}

\author{
${ }^{1}$ Mohammad Saleh, ${ }^{2}$ Atif Iqbal, ${ }^{3}$ SK. Moin Ahmed, ${ }^{4}$ Akhtar Kalam and ${ }^{5}$ Haitham Abu-Rub \\ ${ }^{1}$ Victoria University, Melbourne, AUSTRALIA \\ ${ }^{2}$ Qatar University, QATAR \\ ${ }^{3}$ Texas A\&M University at Qatar, QATAR \\ ${ }^{4}$ Victoria University, Melbourne, AUSTRALIA \\ ${ }^{5}$ Texas A\&M University at QATAR \\ E-mails: arm198@hotmail.com (Mohammad Saleh),atif.iqal@qu.edu.qa (Atif Iqbal),moin.sk@qatar.tamu.edu (SK.Moin Ahmed,), \\ Akhtar.Kalam@vu.edu.au (Akhtar Kalam,), Haitham.abu-rub@qatar.tamu.edu (Haitham Abu-Rub)
}

\begin{abstract}
Multi-phase (more than three-phase) converters are required mainly for feeding variable speed multi-phase drive systems. This paper discusses one such solution by using direct ac-ac converter that can be used to supply a five-phase two-motor drive system. Matrix converter based two-motor drive system is presented for the first time in this paper. Two stator windings of two five-phase machines when connected in seires/parallel while the rotors may be connected to different laods, are called series/parallelconnected two-motor drive. Appropriate phase transposition is introuduced while connecting the series/parallel stator winding to obtain decoupled control of the two machines. This paper proposes simple carrier-based Pulse width modulation (PWM) technique of three-phase to five-phase matrix converter supplying series-connected five-phase AC machine drive system. The developed modulation technique is based on the comparison of high frequency carrier signal with the input voltages, similar to the one used in voltage source inverter. Although carrier-based scheme is widely employed for control of voltage source inverter, it is very recently being used for a matrix converter. The similar concept is extended in this paper for controlling a three-phase to five-phase matrix converter. The major aim of the PWM is to generate two independent fundamental frequency components that will subsequently control two series/parallel connecetd five-phase motor. The viability of the proposed control techniques is proved using analytically and simulation approach.
\end{abstract}

Keywords: Carrier-based PWM, Matrix converter, modulation, five-phase, AC machine, drive

\section{Introduction}

Controlled bidirectional power flow using direct ac-ac conversion using semiconductor switches arranged in the form of matrix array, popularly known as Matrix converter, has recently attracted much attention worldwide. Matrix converter is becoming serious contender to its counterpart voltage source inverter due to some inherent attractive features such as operation at unity power factor for any load, controlled bidirectional power flow, sinusoidal input and output currents etc. A comprehensive overview of the development in the field of matrix converter research is presented in (Wheeler et al, 2002). It is to be noted here that the most common configuration of the matrix converter discussed in the literature are three-phase to three-phase (Kazmierkowaski et al, 2002, Toliyat et al, 2004). Little attention has been paid on the development of matrix converter with output more than three.

The conventional structure for variable-speed drives consists of a three-phase motor supplied by a three-phase power electronic converter. However, when the machine is connected to a modular power electronic converter, such as a voltage source inverter or a matrix converter then the need for a specific number of phases, such as three, disappears. This is due to the fact that by simply adding one leg increases the number of output phases. Nowadays, the development of modern power electronics, makes it possible to consider the number of phases a degree of freedom, i.e., an additional design variable. Multi-phase (more than three) motor drives have some inherent advantages over the traditional three-phase motor drives such as reducing the amplitude and increasing the frequency of torque pulsations, reducing the rotor harmonic currents losses and lowering the dc link current harmonics. In addition, 
owing to their redundant structure, multi-phase motor drives improve the system reliability Detail reviews on the development in the area of multi-phase (more than three-phase) drive are presented in (Singh, 2002, Jones et al, 2002, Bojoi et al, 2006, Levi et al, 2007, Levi, 2008a, Levi, 2008b).

A novel concept for multi-motor drive systems, based on utilization of multi-phase machines and multi-phase inverters, have been proposed recently (Levi et al, 2003a, Levi et al, 2004a, Levi et al, 2004b, Levi et al, 2003b, Iqbal et al, 2005, Yukosovic et al, 2008, Jones et al, 2006, Jones, et al, 2009). Since vector control of any multi-phase machine requires only two stator current components, the additional stator current components are used to control other machines. It has been shown that, by connecting multi-phase stator windings in series (Levi et al, 2003a, Levi et al, 2004a, Levi et al, 2004b, Levi et al, 2003b, Iqbal et al, 2005) and in parallel (Yukosovic et al, 2008, Jones, et al,2006, Jones , et al, 2009) with an appropriate phase transposition, it is possible to control independently all the machines with supply coming from a single multi-phase voltage source inverter. One specific drive system, covered by this general concept, is the five-phase series/parallel-connected two-motor drive, consisting of two five-phase machines and supplied from a single five-phase voltage source inverter. Such topology has been analysed in a considerable depth in (Levi et al, 2003b, Iqbal et al, 2005) for series connection and (Yukosovic et al, 2008, Jones et al, 2006) for parallel connection. The multi-motor drive system discussed so far in the literature uses multi-phase voltage source inverter as their supply. In contrast this paper proposes a multi-phase matrix converter to supply such drive topology.

This paper focuses on the development of novel topology of matrix converter which is a single stage power converter to produce more than three phases. The performance of power electronic converters (ac to ac or ac-dc-ac) is highly dependent on their control algorithms. Thus a number of modulation schemes are developed for voltage source inverters for three-phase output (Holtz, 1992, Holmes, et al, 2003) and multi-phase output (Dujic, et al, 2009a, Dujic, et al, 2009b). Modulation methods of matrix converters are complex and are generally classified in two different groups, called direct and indirect. The direct PWM method developed by Alesina and Venturini (Alesina, et al, 1981) limits the output to half the input voltage. This limit was subsequently raised to 0.866 by taking advantage of third harmonic injection (Alesina, et al, 1989) and it was realized that this is maximum output that can be obtained from a three-to-three phase matrix converter in the linear modulation region. Indirect method assumes a matrix converter as a cascaded virtual three-phase rectifier and a virtual voltage source inverter with imaginary dc link. With this representation, space vector PWM method of VSI is extended to a matrix converter (Casadei, et al, 1993, Huber, et al, 1995). Although the space vector PWM method is suited to three-phase system but the complexity of implementation increases with the increase in the number of switches/phases. Motivated from the simple implementation, carrier-based PWM scheme is introduced recently for three to three phase matrix converter (Wang, et al, 2006, Young, et al, 2006, Poh, et al, 2009).

In this paper, a carrier based PWM strategy is presented based on the comparison of the modulating signals (five-phase target output voltages) with the high frequency triangular carrier wave for a three to five-phase matrix converter. The output voltage is limited to 0.75 of the input voltage magnitude if common-mode voltage is not injected. Another scheme is suggested in the paper utilising the injection of common mode voltage in the output five-phase target voltage. This results in enhanced output voltage equal to 0.7886 of the input magnitude. Theoretically this is the maximum output magnitude that can be obtained in this matrix converter configuration in the linear modulation region. Analytical approach is used to develop and analyse the proposed modulation techniques and are further supported by simulation results. The major aim of the paper is to produce two fundamental frequency output from the matrix converter that can be used to control two series/parallel connected five-phase machines.

\section{Five-phase Two-motor Drive system}

In five-phase system two set of orthogonal voltage/current components are produced namely d-q and $x-y$. In single-motor drive system, only d-q components are utilised and the $\mathrm{x}-\mathrm{y}$ components are free to flow creating losses. Thus concept of two-motor fivephase drive system is developed where both these components are utilised, $d-q$ by one machine and $x-y$ by other machine. The extra set of current components $(x-y)$ available in a five-phase system is effectively utilised in independently controlling an additional five-phase machine when the stator windings of two five-phase machines are connected in series (Fig. 1a)/parallel (Fig. 1b) and are supplied from a single five-phase VSI. In Fig. 1a, reference currents generated by two independent vector controllers, are summed up as per the transposition rules and are supplied to the series-connected five-phase machines. As such the two five-phase machines are supplied from one five-phase inverter but are controlled independently. More detail on this configuration of the drive system is available in (Levi et al, 2003a, Levi et al, 2004a, Levi et al, 2004b, Levi et al, 2003b, Iqbal et al, 2005). The voltage and current relationship of this drive topology is given as;

$$
\begin{array}{ll}
v_{A}^{S}=v_{a 1}+v_{a 2} & i_{A}^{S}=i_{a 1}=i_{a 2} \\
v_{B}^{S}=v_{b 1}+v_{c 2} & i_{B}^{S}=i_{b 1}=i_{c 2} \\
v_{C}^{S}=v_{c 1}+v_{e 2} & i_{C}^{S}=i_{c 1}=i_{e 2} \\
v_{D}^{S}=v_{d 1}+v_{b 2} & i_{D}^{S}=i_{d 1}=i_{b 2} \\
v_{E}^{S}=v_{e 1}+v_{d 2} & i_{E}^{S}=i_{e 1}=i_{d 2}
\end{array}
$$


Here, $s$ stand for source quantity, capital letters denote source output and small letters represents motor side quantities.

Another analogues stator winding connection of five-phase two-motor drive is parallel-connected drive (Fig.1b) which is directly derived from the analogy of series and parallel circuits. The source (three to five-phase matrix converter) supplied both the machines and these machine are connected in parallel with appropriate phase transposition (Vukosovic et al, 2008, Jones, et al, 2006, Jones , et al, 2009). The control decoupling is possible due to decoupling of the $\alpha-\beta$ and $x-y$ components. The d-q components of one machine become the $x-y$ to the other and vice-versa. Here the vector controller produced voltage references in contrary to series-connected drive where current references are generated from the vector controller. Once again independent control is achieved of the two five-phase motors. The voltage and current relations for this drive topology are given as;

$$
\begin{array}{ll}
v_{A}^{S}=v_{a 1}=v_{a 2} \\
v_{B}^{S}=v_{b 1}=v_{c 2} \\
v_{C}^{S}=v_{c 1}=v_{e 2} \\
v_{D}^{S}=v_{d 1}=v_{b 2} \\
v_{E}^{S}=v_{e 1}=v_{d 2}
\end{array}
$$

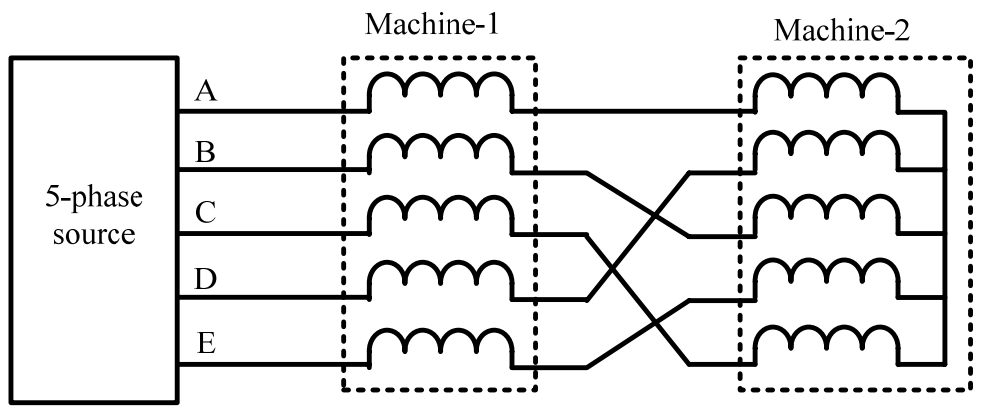

Fig.1a Five-phase series-connected two-motor drive structure

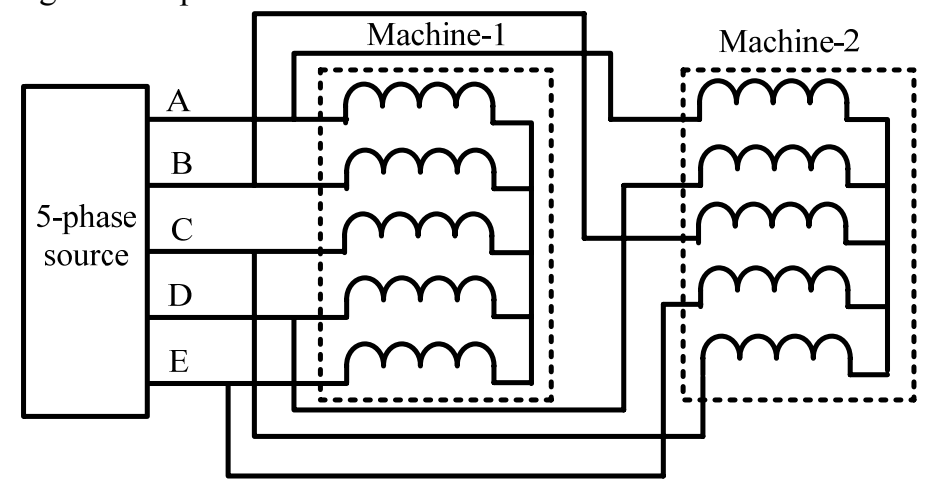

Fig. 1b. Five-phase parallel-connected two-motor drive structure

If current control in the rotating reference frame is to be utilized, appropriate PWM scheme for five-phase VSI needs to be developed to generate voltage references instead of current references for both series and parallel connected drives. The PWM technique developed and reported in the paper thus produces two-frequency voltage reference output.

\section{Three-to-Five Matrix Converter}

The power circuit topology of a three-phase to five-phase matrix converter is illustrated in Fig. 2. There are five legs with each leg having three bidirectional power switches connected in series. Each power switch is bidirectional in nature with anti-parallel connected IGBTs and diodes. The input is similar to a three-phase to three-phase matrix converter having LC filters and the output is five-phases with $72^{\circ}$ phase displacement between each phases. 


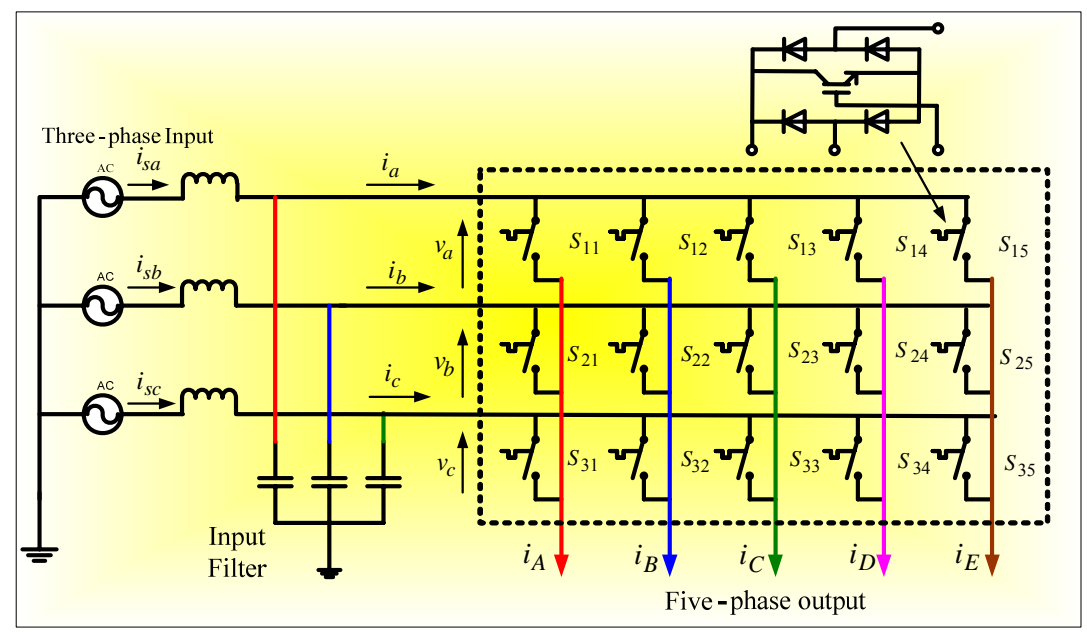

Fig. 2. Power Circuit topology of Three-phase to five-phase matrix converter

The load to the matrix converter is assumed as star-connected five-phase ac machine. Switching function is defined as $\mathrm{S}_{j k}=\{1$ for closed switch, 0 for open switch $\}, j=\{a, b, c\}$ (input), $k=\{A, B, C, D, E\}$ (output). The switching constraint is $\mathrm{S}_{a k}+\mathrm{S}_{b k}+$ $\mathrm{S}_{c k}=1$.

The modulation technique is developed by assuming input side as three-phase controlled rectifier and the output is a five-phase voltage source inverter with a fictitious dc link.

\section{Carrier-Based Pulse Width Modulation Technique for Two-motor Drives}

Carrier-based PWM scheme developed in this section follows the similar concept presented in (Jones, et al, 2009). Since the input side is three-phase, the analytical treatment remains the same as that of (Jones, et al, 2009). However, the output is now increased to five and hence the analysis will be modified to suit the requisite output phase number. A balanced three-phase system is assumed at the input and unbalance study will be reported separately.

$$
\begin{aligned}
& v_{a}=|V| \cos (\omega t) \\
& v_{b}=|V| \cos (\omega t-2 \pi / 3) \\
& v_{b}=|V| \cos (\omega t-4 \pi / 3)
\end{aligned}
$$

Since the matrix converter outputs voltages with frequency decoupled from the input voltages, the duty ratios of the switches are to be calculated accordingly. The five-phase output voltage duty ratios should be calculated in such a way that output voltages remains independent of input frequency. In other words, the five-phase output voltages can be considered in synchronous reference frame and the three-phase input voltages can be considered to be in stationary reference frame, so that the input frequency term will be absent in output voltages. Considering the above, duty ratios of output phase $j$ is chosen as

$$
\begin{aligned}
& \delta_{a j}=k_{j} \cos (\omega t-\rho), \\
& \delta_{b j}=k_{j} \cos (\omega t-2 \pi / 3-\rho), \\
& \delta_{c j}=k_{j} \cos (\omega t-4 \pi / 3-\rho)
\end{aligned}
$$

Where $\rho$ is the phase shift at the input side. The input and output voltages are related as:

$$
\left[\begin{array}{c}
V_{A} \\
V_{B} \\
V_{C} \\
V_{D} \\
V_{E}
\end{array}\right]=\left[\begin{array}{lll}
\delta_{a A} & \delta_{b A} & \delta_{c A} \\
\delta_{a B} & \delta_{b B} & \delta_{c B} \\
\delta_{a C} & \delta_{b C} & \delta_{c C} \\
\delta_{a D} & \delta_{b D} & \delta_{c D} \\
\delta_{a E} & \delta_{b E} & \delta_{c E}
\end{array}\right]\left[\begin{array}{l}
V_{a} \\
V_{b} \\
V_{c}
\end{array}\right]
$$

Therefore the phase A output voltage can be obtained by using the above duty ratios as

$$
V_{A}=k_{A}|V|[\cos (\omega t) \bullet \cos (\omega t-\rho)+\cos (\omega t-2 \pi / 3) \bullet \cos (\omega t-2 \pi / 3-\rho)+\cos (\omega t-4 \pi / 3) \bullet \cos (\omega t-4 \pi / 3-\rho)]
$$


In general equation (6) can be written as

$$
V_{A}=\frac{3}{2} k_{A}|V| \cos (\rho)
$$

In eq (7), $\cos (\rho)$ term indicates that the output voltage is affected by $\rho$. The term $k_{A}$ is defined in equation (10). Thus, the output voltage $V_{A}$ is independent of the input frequency and only depends on the amplitude $|V|$ of the input voltage and $k_{A}$ is a reference output voltage time-varying modulating signal for the output phase A with the desired output frequency $\omega_{01}+\omega_{o 2}, \omega_{o 1}$ is the operating frequency of machine- 1 or the first fundamental output frequency and $\omega_{02}$ is the operating frequency of machine- 2 or the second fundamental output frequency. The fundamental output voltage magnitude corresponding to $\omega_{o 1}$ is given as $m_{1}$ and corresponding to $\omega_{O 2}$ is given as $m_{2}$. The five-phase reference output voltages can then be represented as

$$
\begin{aligned}
& k_{A 1}=m_{1} \cos \left(\omega_{o 1} t\right), \\
& k_{B 1}=m_{1} \cos \left(\omega_{o 1} t-2 \pi / 5\right) \\
& k_{C 1}=m_{1} \cos \left(\omega_{o 1} t-4 \pi / 5\right) \\
& k_{D 1}=m_{1} \cos \left(\omega_{o 1} t-6 \pi / 5\right) \\
& k_{E 1}=m_{1} \cos \left(\omega_{o 1} t-8 \pi / 5\right)
\end{aligned}
$$

$$
\begin{aligned}
& k_{A 2}=m_{2} \cos \left(\omega_{O 2} t\right) \\
& k_{B 2}=m_{2} \cos \left(\omega_{O 2} t-2 \pi / 5\right) \\
& k_{C 2}=m_{2} \cos \left(\omega_{O 2} t-4 \pi / 5\right) \\
& k_{D 2}=m_{2} \cos \left(\omega_{O 2} t-6 \pi / 5\right) \\
& k_{E 2}=m_{2} \cos \left(\omega_{O 2} t-8 \pi / 5\right) \\
& k_{A}=k_{A 1}+k_{A 2} \\
& k_{B}=k_{B 1}+k_{C 2} \\
& k_{C}=k_{C 1}+k_{E 2} \\
& k_{D}=k_{D 1}+k_{B 2} \\
& k_{E}=k_{E 1}+k_{D 2}
\end{aligned}
$$

Therefore, from (7), the output voltages are obtained as;

$$
\begin{aligned}
& V_{A}=\left[\frac{3}{2} k_{A 1}|V| \cos (\rho)\right] \cos \left(\omega_{O 1} t\right)+\left[\frac{3}{2} k_{A 2}|V| \cos (\rho)\right] \cos \left(\omega_{o 2} t\right) \\
& V_{B}=\left[\frac{3}{2} k_{B 1}|V| \cos (\rho)\right] \cos \left(\omega_{O 1} t-2 \frac{\pi}{5}\right)+\left[\frac{3}{2} k_{C 2}|V| \cos (\rho)\right] \cos \left(\omega_{O 2} t-4 \frac{\pi}{5}\right) \\
& V_{C}=\left[\frac{3}{2} k_{C 1}|V| \cos (\rho)\right] \cos \left(\omega_{o 1} t-4 \frac{\pi}{5}\right)+\left[\frac{3}{2} k_{E 2}|V| \cos (\rho)\right] \cos \left(\omega_{o 2} t-8 \frac{\pi}{5}\right) \\
& V_{D}=\left[\frac{3}{2} k_{D 1}|V| \cos (\rho)\right] \cos \left(\omega_{o 1} t-6 \frac{\pi}{5}\right)+\left[\frac{3}{2} k_{D 2}|V| \cos (\rho)\right] \cos \left(\omega_{O 2} t-2 \frac{\pi}{5}\right) \\
& V_{E}=\left[\frac{3}{2} k_{E 1}|V| \cos (\rho)\right] \cos \left(\omega_{o 1} t-8 \frac{\pi}{5}\right)+\left[\frac{3}{2} k_{D 2}|V| \cos (\rho)\right] \cos \left(\omega_{o 2} t-6 \frac{\pi}{5}\right)
\end{aligned}
$$

\section{A Application of Offset Duty Ratio}

In the above discussion, duty-ratios become negative (see eq. (5)) which are not practically realizable. For the switches connected to output phase- $A$, at any instant, the condition $0 \leq \mathrm{d}_{\mathrm{aA}}, \mathrm{d}_{\mathrm{bA}}, \mathrm{d}_{\mathrm{cA}} \leq 1$ should be valid. Therefore, offset duty ratios should to be added to the existing duty-ratios, so that the net resultant duty-ratios of individual switches are always positive. Furthermore, 
the offset duty-ratios should be added equally to all the output phases to ensure that the effect of resultant output voltage vector produced by the offset duty-ratios is null in the load. That is, the offset duty-ratios can only add the common-mode voltages in the output. Considering the case of output phase-A;

$$
\delta_{a A}+\delta_{b A}+\delta_{c A}=k_{A} \cos (\omega t-\rho)+k_{A} \cos (\omega t-2 \pi / 3-\rho)+k_{A} \cos (\omega t-4 \pi / 3-\rho)=0
$$

Absolute values of the duty-ratios are added to cancel the negative components from individual duty ratios. Thus the minimum individual offset duty ratios should be

$$
\begin{aligned}
& D_{a}(t)=\left|\delta_{a A}\right|=\left|k_{A} \cos (\omega t-\rho)\right| \\
& D_{b}(t)=\left|\delta_{b A}\right|=\left|k_{A} \cos (\omega t-2 \pi / 3-\rho)\right| \\
& \text { and } \\
& D_{c}(t)=\left|\delta_{c A}\right|=\left|k_{A} \cos (\omega t-4 \pi / 3-\rho)\right|
\end{aligned}
$$

The effective duty ratios are

$$
\begin{aligned}
& \delta_{a A}^{\prime}=\delta_{a A}+D_{a}(t), \\
& \delta_{b A}^{\prime}=\delta_{b A}+D_{b}(t), \\
& \delta_{c A}^{\prime}=\delta_{c A}+D_{c}(t)
\end{aligned}
$$

Other output phases can be written in the similar fashion. The net duty ratio $0 \leq \delta_{\mathrm{ak}}^{\prime} \leq 1$ should be within the range of 0 to 1 .

For the worst case

$$
0 \leq 2 .\left|k_{A}\right| \leq 1
$$

The maximum value of $k_{A}$ is equal to 0.5 . In any switching cycle the output phase should not be open circuited. Thus the sum of the duty ratios in (13) must equal unity. But the summation $D_{a}(t)+D_{b}(t)+D_{c}(t)$ is less than or equal to unity. Hence another offset duty-ratio $\left[1-\left\{D_{a}(t)+D_{b}(t)+D_{c}(t)\right\}\right] / 3$ is added to $D_{a}(t), D_{b}(t)$ and $D_{c}(t)$ in (13). The addition of this offset duty-ratio in all switches will maintain the output voltages and input currents unaffected. Similarly, the duty-ratios are calculated for the other five output phases.

If $k_{A}, k_{B}, k_{C}, k_{D}, k_{E}$ are chosen to be 5-phase sinusoidal references as given in equation (9), the input voltage capability is not fully utilized for output voltage generation and the output magnitude remains only $50 \%$ of the input magnitude. To overcome this, an additional common mode term equal to $\left.\left\{\max \left(k_{A}, k_{B}, k_{C}, k_{D}, k_{E}\right)+\min \left(k_{A}, k_{B}, k_{C}, k_{D}, k_{E}\right)\right\} / 2\right]$ is added as in the carrier-based PWM principle as implemented in two-level inverters. Thus the amplitude of $\left(k_{A}, k_{B}, k_{C}, k_{D}, k_{E}\right)$ can be enhanced from 0.5 to 0.5257 .

\section{B Without Common-mode voltage addition}

In the above section, two offsets are added to the original duty ratios to form the following effective duty ratio for output phase $\mathrm{p}$;

$$
\begin{aligned}
& \Delta_{a p}=D_{a}(t)+\left(1-\left\{D_{a}(t)+D_{b}(t)+D_{c}(t)\right\}\right) / 3+k_{p} \times \cos (\omega t-\rho) \\
& \Delta_{b p}=D_{b}(t)+\left(1-\left\{D_{a}(t)+D_{b}(t)+D_{c}(t)\right\}\right) / 3+k_{p} \times \cos (\omega t-2 \pi / 3-\rho) \\
& \Delta_{c p}=D_{c}(t)+\left(1-\left\{D_{a}(t)+D_{b}(t)+D_{c}(t)\right\}\right) / 3+k_{p} \times \cos (\omega t-4 \pi / 3-\rho)
\end{aligned}
$$

Where $p \in A, B, C, D, E, F$

These duty ratios (equation (16)) can be compared to the triangular carrier wave to generate the gating signals for the bidirectional power switches. The output phase voltage magnitude will reach $75 \%$ of the input voltage magnitude with this method. To further enhance the output voltage magnitude, common mode voltage of the output reference signals are added to formulate the new duty ratios as discussed in the next section. 
IV C

\section{With Common mode voltage Addition}

The duty ratios can further be modified by injection common mode voltage of the output voltage references to improve the output voltage magnitude. The output voltage magnitude increases and reaches its limiting value of $78.8 \%$ of the input magnitude. The common mode voltage that is added to obtain new duty ratios are;

$$
V_{c m}=-\frac{V_{M a x}-V_{M i n}}{2}
$$

Where

$$
\begin{aligned}
& V_{\text {max }}=\max \left\{k_{A}, k_{B}, k_{C}, k_{D}, k_{E}, k_{F}\right\} \\
& V_{\text {min }}=\min \left\{k_{A}, k_{B}, k_{C}, k_{D}, k_{E}, k_{F}\right\}
\end{aligned}
$$

The duty ratio for output phase $\mathrm{p}$ can be written as;

$$
\begin{aligned}
& d_{a p}=D_{a}(t)+\left(1-\left\{D_{a}(t)+D_{b}(t)+D_{c}(t)\right\}\right) / 3+\left[k_{p}+V_{c m}\right] \times \cos (\omega t-\rho) \\
& d_{b p}=D_{b}(t)+\left(1-\left\{D_{a}(t)+D_{b}(t)+D_{c}(t)\right\}\right) / 3+\left[k_{p}+V_{c m}\right] \times \cos (\omega t-2 \pi / 3-\rho) \\
& d_{c p}=D_{c}(t)+\left(1-\left\{D_{a}(t)+D_{b}(t)+D_{c}(t)\right\}\right) / 3+\left[k_{p}+V_{c m}\right] \times \cos (\omega t-4 \pi / 3-\rho)
\end{aligned}
$$

Where $\mathrm{p} \in \mathrm{A}, \mathrm{B}, \mathrm{C}, \mathrm{D}, \mathrm{E}, \mathrm{F}$

The five-phase output voltages can be written as;

$$
\begin{aligned}
& k_{A}=m_{1} \cos \left(\omega_{O 1} t\right)+m_{2} \cos \left(\omega_{O 2} t\right) \\
& k_{B}=m_{1} \cos \left(\omega_{O 1} t-2 \pi / 5\right)+m_{2} \cos \left(\omega_{O 2} t-4 \pi / 5\right) \\
& k_{C}=m_{1} \cos \left(\omega_{O 1} t-4 \pi / 5\right)+m_{2} \cos \left(\omega_{O 2} t-8 \pi / 5\right) \\
& k_{D}=m_{1} \cos \left(\omega_{O 1} t-6 \pi / 5\right)+m_{2} \cos \left(\omega_{O 2} t-6 \pi / 5\right) \\
& k_{E}=m_{1} \cos \left(\omega_{O 1} t-8 \pi / 5\right)+m_{2} \cos \left(\omega_{O 2} t-2 \pi / 5\right)
\end{aligned}
$$

Where $\omega$ is input frequency and $\omega_{01}$ and $\omega_{02}$ are the output frequencies of machine-1 and machine-2 respectively, $m_{1}$ and $m_{2}$ are the modulation indices for machine- 1 and machine 2, respectively. For unity power factor $\rho$ has to chosen zero. The modulating signals are shown in Fig. 4, after adding the output common mode voltages. These duty ratios (equation (19)) are then compared with the high frequency triangular carrier signals to generate the gating signals as illustrated in Fig. 3, for phase A. Similarly fifteen more duty ratios will be compared with the triangular carrier to generate overall gating signals.

A complete block schematic of the PWM signal generation is presented in Fig. 4. The reference voltages for two machines with the desired speeds and appropriate voltage magnitudes are generated. These references are then summed according to the phase transposition rule. The overall modulating signal thus generated is given to the PWM block. This PWM block then generate appropriate gate signals for the matrix converter. The matrix converter then produces appropriate voltages which drive the two series/parallel connected machines.

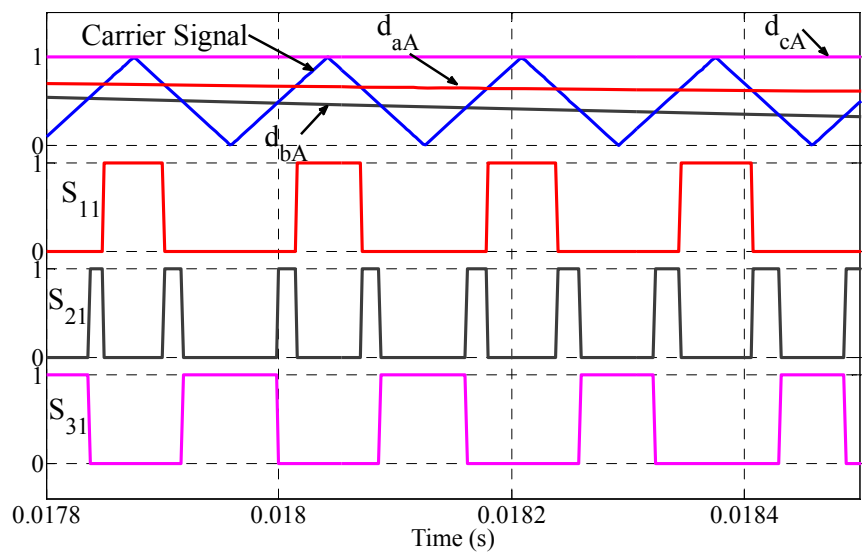

Fig. 3. Gate signal generation for output phase A. 


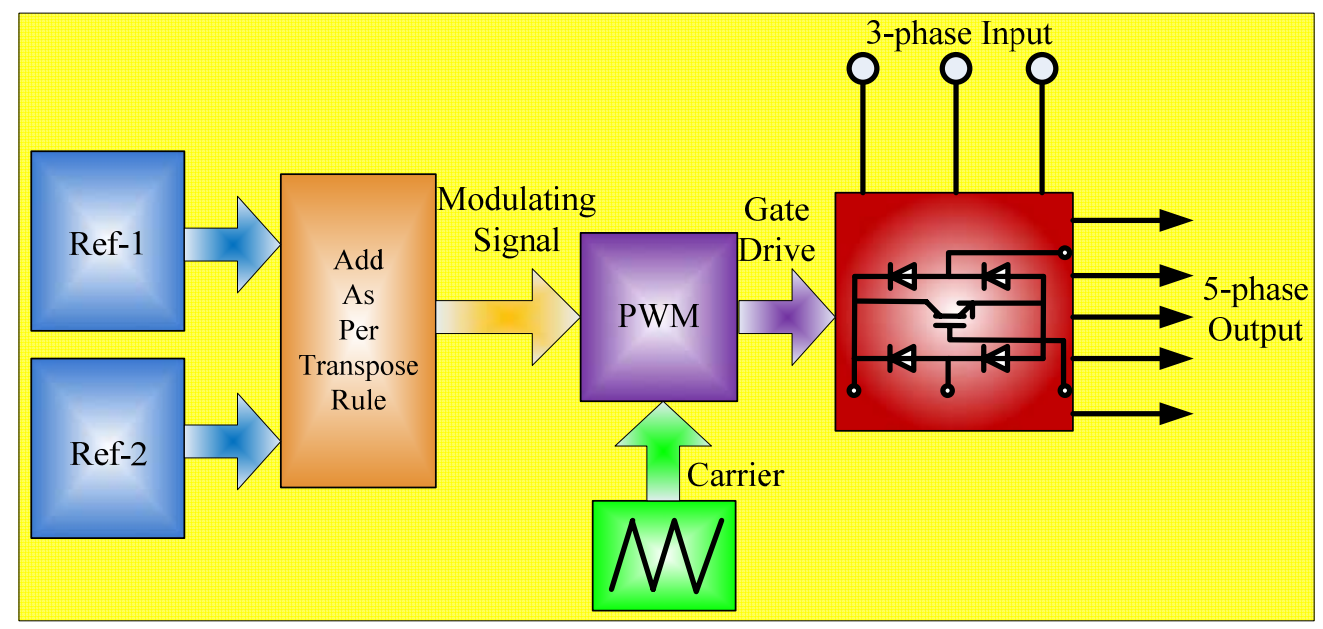

Fig. 4. Block diagram of Carrier-based PWM for two frequency output

\section{Simulation Results}

Matalab/Simulink model is developed for the proposed matrix converter control. The input voltage is fixed at $100 \mathrm{~V}$ to show the exact gain at the output side. The switching frequency of the devices is kept at $6 \mathrm{kHz}$. The purpose here is to show two fundamental components of current produced by the matrix converter. These voltage components are independent from each other and thus can independently control the two machines. The results shown here is only limited to the production of the appropriate voltage components. The motor behaviour is not discussed in this paper and will be reported separately. It is assumed that one voltage component has frequency of $30 \mathrm{~Hz}$ and second voltage component has $60 \mathrm{~Hz}$. To respect the $\mathrm{v} / \mathrm{f}=$ constant control the voltage magnitude of the lower frequency component is half compared to the higher frequency component. For the simulation purpose a R-L load is connected with $\mathrm{R}=10 \Omega$ and $\mathrm{L}=10 \mathrm{mH}$. Simulation results are shown for the modulation with common mode voltage addition in the output target voltage. Thus the maximum output of the matrix converter is limited to $78.8 \mathrm{~V}$ as the input is $100 \mathrm{~V}$. The results without common mode voltage addition will remain the same except with the lower output magnitude.

The resulting waveforms are presented in Fig. 5a,b to 7. The input source side and converter side waveforms are presented in Fig. 5a,b. The results clearly shows unity power factor at the input side. The converter side current shows PWM signal and the spectrum is clearly sinusoidal with no lower order harmonics.

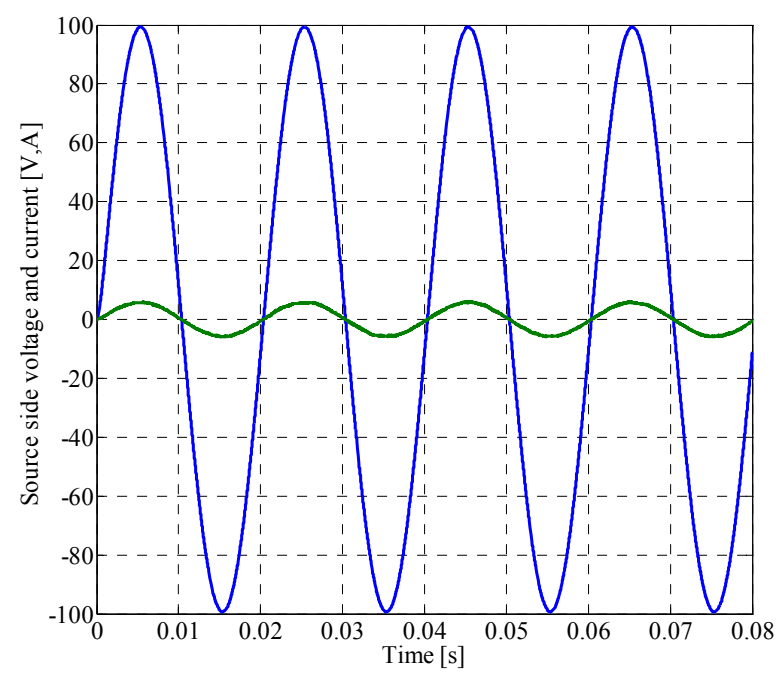

Fig. 5a. Input side waveforms of 3 to 5-phase Matrix Converter: upper trace 


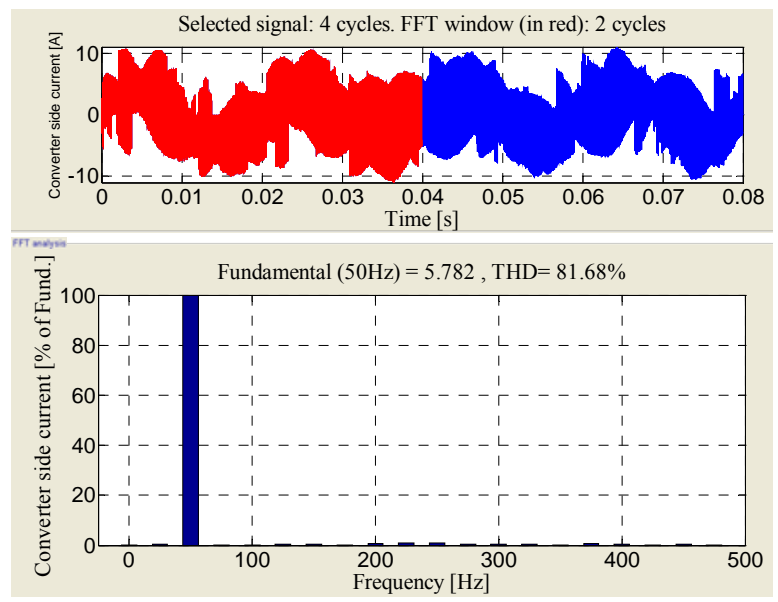

Fig. 5b. Input voltage and current, bottom trace, Spectrum Input current.

The output side filtered voltages are given in Fig. 6 and the spectrum of the output PWM signal voltages are presented in Fig. $7 \mathrm{a}, \mathrm{b}, \mathrm{c}$. The output filtered phase voltages shows superimposed fundamental and second harmonic components. The spectrum of phase 'A' voltage and the transformed voltage are given in Fig. 7a,b,c. It is clearly evident that the phase 'A' voltage contains two fundamental components at $30 \mathrm{~Hz}$ and $60 \mathrm{~Hz}$. These voltages are then decoupled and appear in $\alpha-\beta$ plane $(60 \mathrm{~Hz})$ and $\mathrm{x}-\mathrm{y}$ plane $(30 \mathrm{~Hz})$. Thus is aim of the control is achieved. Also the magnitude of the two voltages follows $v / f=$ constant rule.

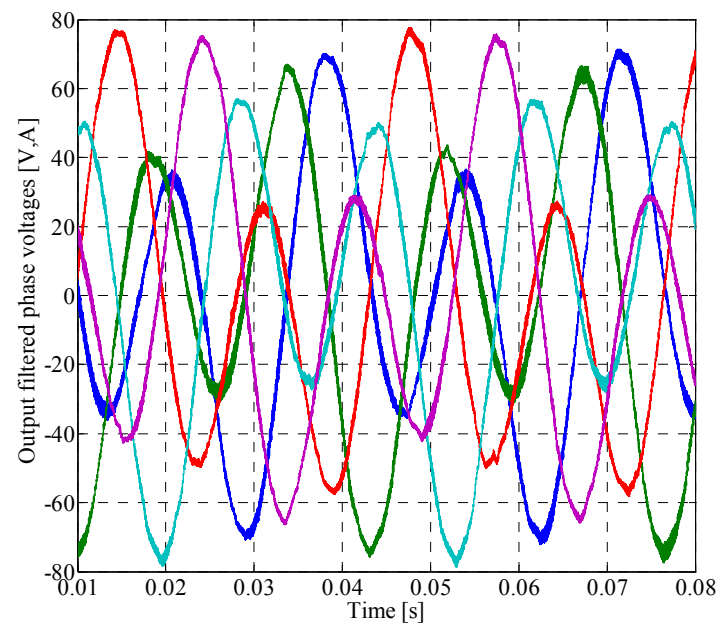

Fig. 6. Output filtered five-phase voltages

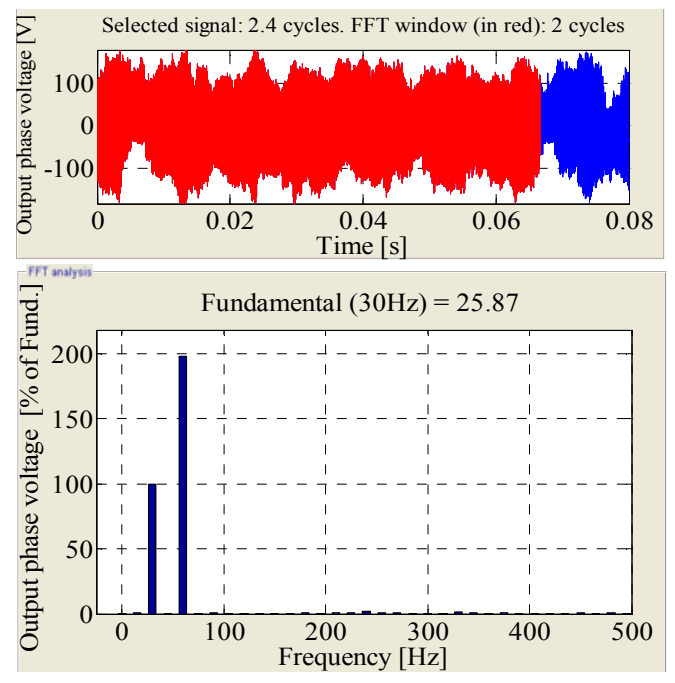

Fig. 7a. Spectrum of output voltages; phase 'A'

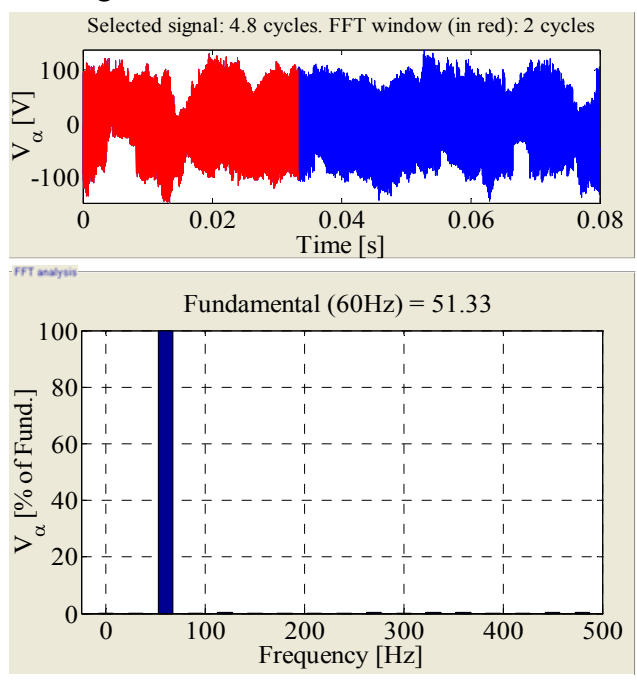

Fig. 7b. Spectrum of output voltages; $\alpha$-axis voltage 


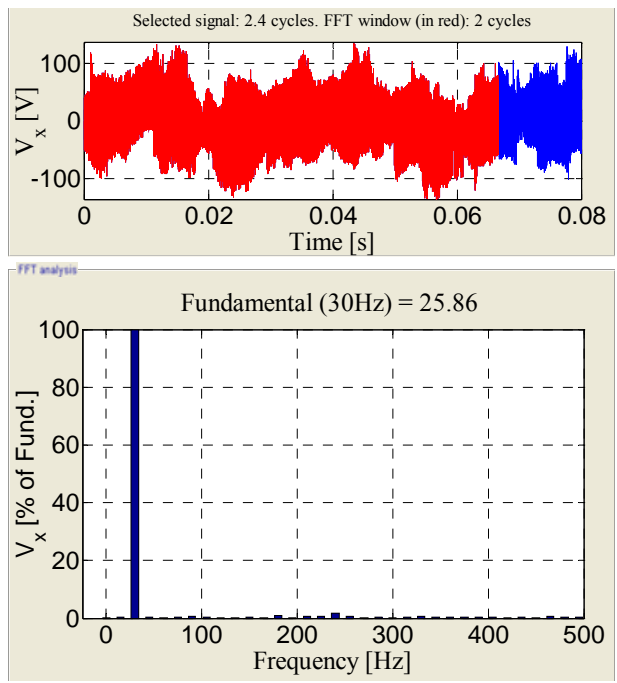

c.

Fig. 7c. Spectrum of output voltages; $x$-axis voltage.

\section{Conclusion}

The paper presents a novel solution for supplying five-phase series/parallel connected two-motor drive system using a threephase input to five-phase output matrix converter The input to the matrix converter is three-phase ac supply and the output is fivephase variable voltage and variable frequency. It possesses all the advantages offered by a conventional matrix converter, however, the output voltage magnitude is found to be limited to $78.86 \%$ of the input voltage magnitude in the linear modulation region. The proposed PWM strategy is derived from the analogy of the modulation of a voltage source inverter. The analytical findings are confirmed using simulation approach. The decoupled voltage components are realized. The proposed structure will be further studied for feeding a five-phase two-motor drive and the drive behaviour will be investigated.

\section{Nomenclature:}

$v_{k 1}, i_{k 1}$

$v_{k 2}, i_{k 2}$

$\delta_{a j}$

$\delta_{b j}$

$\delta_{c j}$

$V_{\max }$

$V_{\min }$

$V_{c m}$

$m_{1}$

$m_{2}$

$k_{j}$
Stator voltages and currents, respectively for machine 1

Stator voltages and currents, respectively for machine 2

Duty ratio of input phase ' $a$ ' and output phase ' $j$ '

Duty ratio of input phase ' $b$ ' and output phase ' $j$ '

Duty ratio of input phase 'c' and output phase ' $j$ '

Maximum of output/input voltages

Minimum of output/input voltages

Common mode voltage

Modulation index for machine 1

Modulation index for machine 2

Output voltage references

\section{References}

Alesina, A. and Venturini, M, 1981. Solid state power conversion: A Fourier analysis approach to generalised transformer synthesis. IEEE Trans. Circuit System, Vol. 28, No. CS-4, pp. 319-330, April.

Alesina, A. and Venturini, M, 1989. Analysis and design of optimum amplitude nine-switch direct ac-ac converters. IEEE Trans. Power Elect. Vol. PE-4, No. 1, pp. 101-112.

Bojoi, R., Farina, F., Profumo, F., and Tenconi, 2006. Dual three induction machine drives control-A survey. IEEJ Tran. On Ind. Appl.,Vol. 126, No. 4, pp. 420-429.

Casadei, D, Grandi, G., Serra, G. and Tani, A, 2009. Space vector control of matrix converters with unity power factor and sinusoidal input/output waveforms. Proc. EPE Conf., Vol. 7, pp. 170-175, 1993. 
Dujic, D., Jones, M., Levi, E., 2009a. Analysis of output current ripple rms in multi-phase drives using space vector approach. IEEE Trans. On Power Elect. Vol. 24, No. 8, pp. 1926-1938, Aug.

Dujic, D., Jones, M., and Levi, E., 2009b, Generalised space vector PWM for sinusoidal output voltage generation with multiphase voltage source inverts, Int. Journal of Ind. Elect. and Drives, Vol. 1, No.1, pp. 1-13.

Holmes, D.G., and Lipo, T.A., 2003, Pulse width modulation for power converters: Principle and Practice, Piscataway, NJ: IEEE Press.

Holtz, J., 1992. Pulsewidth modulation-A survey, IEEE Trans. On Ind. Elect., Vol. 39, No. 5, pp. 410-420, Dec..

Huber, L., and Borojevic, D, 1995, Space vector modulated three-phase to three-phase matrix converter with input power factor correction, IEEE Trans. Ind. Appl. Vol. 31, No. 6, pp. 1234-1246, Nov./Dec..

Iqbal, A., Vukosavic, S.N, Levi, E., Jones, M., Toliyat, H.A. 2005. Dynamics of a series-connected two-motor five-phase drive system with a single-inverter supply, IEEE Ind. Appl. Society Annual Meeting IAS, Hong Kong, pp. 1081-1088.

Jones, M., and Levi, E, 2002, A literature survey of state-of-the-art in multiphase ac drives, Proc. $37^{\text {th }}$ Int. Universities Power Eng. Conf. UPEC, Stafford, UK, pp. 505-510.

Jones, M., Levi, E., and Vukosavic, S.N., 2006. Independent control of two five-phase induction machines connected in parallel to a single inverter supply. Proc. IEEE IECON, pp. 1257-1262.

Jones, M., Vukosavic S.N., and Levi, E., 2009. Parallel-connected multiphase multi-drive systems with single inverter supply. IEEE Trans. On Ind. Elect., Vol. 56, No. 6, pp. 2047-2057.

Kazmierkowaski, M.P., Krishnan, R., and Blaabjerg, F, 2002. Control in Power Electronics-Selected problems. Academic Press, USA.

Levi, E., Bojoi,R., Profumo, F., Toliyat, H.A, and Williamson, S. 2007. Multi-phase induction motor drives-A technology status review. IET Elect. Power Appl. Vol. 1, No. 4, pp. 489-516, July.

Levi, E. 2008a Guest editorial, IEEE Trans. Ind. Electronics, Vol.55, No. 5, May 2008, pp. 1891-1892.

Levi, E. 2008b. Multi-phase Machines for variable speed applications. IEEE Trans. On Ind. Elect. Vol. 55, No. 5, May, pp. 18931909.

Levi, E., Iqbal, A., Vukosavic, S.N., and Toliyat, H.A., 2003. Modelling and control of a five-phase series-connected two-motor drive. Proc. IEEE Ind. Elec. Society, Annual Meeting IECON, Roanoke, Virginia, pp. 208-213.

Levi, E., Jones, M., and Vukosavic, S.N. 2003. Even-phase multi-motor vector controlled drive with single inverter supply and series connection of stator windings. IEE Proc. - Electric Power Applications, Vol. 150, No. 5, pp. 580-590.

Levi, E., Jones, M., Vukosavic, S.N., Toliyat, H.A., 2004a. A novel concept of a multi-phase, multi-motor vector controlled drive system supplied from a single voltage source inverter. IEEE Trans. on Power Electronics, Vol. 19, No. 2, pp. 320-335.

Levi, E., Jones, M., Vukosavic, S.N., Toliyat, H.A., 2004b. A five-phase two-machine vector controlled induction motor drive supplied from a single inverter. EPE Journal, Vol. 14, No. 3, pp. 38-48.

Poh C., Loh, R. Rong, F. Blaabjerg and P. Wang, 2009. Digital carrier modulation and sampling issues of matrix converter. IEEE Trans. On Power Elect., Vol. 24, No. 7, July.

Toliyat, H.A., and Campbell, S, 2004. : DSP based Electromechanical Motion Control, CRC Press, USA.

Vukosavic, S.N., Jones, M., Levi, E., and Dujic, D., 2008. Experimental performance evaluation of a five-phase parallel-connected two-motor drive. Prof. Int. conf. on Power Electronics, machines and drives, PEMD-2008, pp. 686-690.

Wheeler, P.W., Rodriguez, J., Clare, J,C., Empringham, L., and Weinstein,A., 2002, Matrix converters: a technology review. IEEE Trans. On Ind. Elect. Vol. 49, No. 2, April, pp. 276-288.

Wang, B., and Venkataramanan,G. 2006. A carrier-based PWM algorithm for indirect matrix converters. in Proc. IEEE-PESC 2006, pp. 2780-2787.

Young-Doo Yoon and Seung-Ki Sul. 2006. Carrier-based modulation technique for matrix converter. IEEE Trans. Power Elect., Vol. 21, No. 6, pp. 1691-1703, November.

\section{Biographical notes}

Mohammad Saleh is Master in Telecommunication and Post Graduate diploma in Education and Training from Victoria University. He has completed his Bachelor of Electrical Engineering from University of North Carolina at Charlotte, USA in 1989. He is presently employed at Qatar Petroleum, Qatar and also registered at Victoria University, Australia for his $\mathrm{PhD}$ degree.

Atif Iqbal Atif Iqbal received his B.Sc. and M.Sc. Engineering (Electrical) degrees in 1991 and 1996, respectively, from the Aligarh Muslim University, Aligarh, India and PhD in 2006 from Liverpool John Moores University, UK. He has been employed as Lecturer in the Department of Electrical Engineering, Aligarh Muslim University, Aligarh since 1991 and is working as Associate Professor in the same university. He is presently with Texas A\&M University at Qatar on research assignment. He is recipient of Maulana Tufail Ahmad Gold Medal for standing first at B.Sc. Engg. Exams in 1991 at AMU, and EPSRC, Govt. Of UK, fellowship from 2002-2005 for pursuing PhD studies. His principal research interest is Modelling and Control of Power Electronics Converters \& Drives.

SK. Moin Ahmed born in 1983 at Hoogly, West Bengal, India. He received his B.Tech (Electrical) and M.Tech. (Power System \& drives) in 2006 \& 2008, respectively, from Department of Electrical Engineering, Aligarh Muslim University, Aligarh. He is gold medalist for securing top position in M.Tech. He is a recipient of Torento fellowship funded by AMU. Currently he is pursuing his PhD at AMU and employed as Senior research fellow in a CSIR, New Delhi, funded project. 
Akhtar Kalam - Professor Akhtar Kalam has been at Victoria University, Melbourne since 1985 and a former Deputy Dean of the Faculty of Health, Engineering and Science for 7 years. He has wide experience in educational institutions and industry across four continents. He received his B.Sc. and B.Sc. Engineering from Calcutta University and Aligarh Muslim University, India in 1969 and 1973 respectively. He completed his MS and Ph.D. at the University of Oklahoma, USA and the University of Bath, UK in 1975 and 1981 respectively. He has held teaching appointments at the University of Technology, Baghdad, Iraq and Capricornia Institute of Advanced Education, Rockhampton, Queensland. He is regularly invited to deliver lectures, work on industrial projects and examine external thesis overseas. His major areas of interests are power system analysis, communication, control, protection and cogeneration systems. He has been actively engaged in the teaching of Energy Systems to undergraduates, postgraduates and providing professional courses to the industry both in Australia and overseas. He regularly offers professional development courses on Power System Protection, Renewable Energy and Cogeneration \& Gas Turbine Operation to the Energy Supply Association of Australia (ESAA) and Australian Power Institute (API). He also runs postgraduate distance education programme on Power System Protection for the ESAA. He has conducted research, provided industrial consultancy and published over three hundred and fifty seven publications on his area of expertise and written over 29 books in the area. Professor Kalam is a Fellow of EA, IET, AIE and a member of IEEE.

Haitham Abu-Rub has done his PhD from Gdansk University, Poland in 1995 and MSc in Electrical Engg From Gdynia Maritime University. He is presently serving as Visiting Senior Associate Professor in the Deptt. Of Electrical \& Computer Engg., Texas A\&M University at Qatar. His area of interest are Field oriented control of electrical machines, nonlinear control of electrical drive, sensorless control, parameters estimation, power electronics, and electrical machines. Has earned many international prestigious awards like the American Fulbright Scholarship (Texas A\&M University), the German Alexander von Humboldt Fellowship (Wuppertal university), the German DAAD Scholarship (Bochum University), and the British Royal Society Scholarship (Southampton University). Also received the "Best Presentation Award" at the 27th Annual Conference of the IEEE Industrial Electronics Society in Denver (IECON'01).

Received September 2010

Accepted November 2010

Final acceptance in revised form December 2010 